\title{
CoSMETIC NEUROCOGNITIVE ENHANCEMENT AND HEALTHCARE PROVIDERS
}

\author{
Tracy D. Gunter M.D.**
}

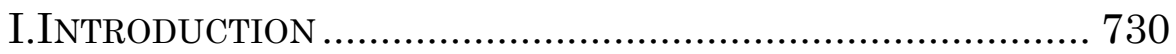

II. NeUrocognitive Enhancement In Health CARE ..... 732

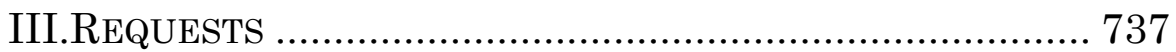

A. Neuromyths Facilitating Requests ........................ 737

B. Direct-to-Consumer Advertising as a Driver

of Patient Requests..................................................... 739

C. So What Is It That People Do (and Do Not)

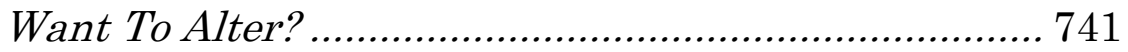

IV. RESPONSES: PROVIDER ISSUES...................................... 745

A. Models of Provider-Patient Interactions.................. 746

B. Provider Attitudes About Enhancement ................. 749

C. Availability of Enhancing Drugs (Off-Label

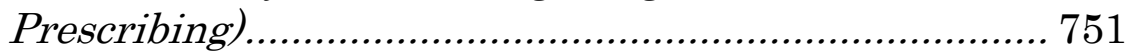

D. Currently Available Enhancing Drugs ................... 753

1. Schedule II Drugs ............................................. 753

2. Schedule IV Drugs ............................................ 756

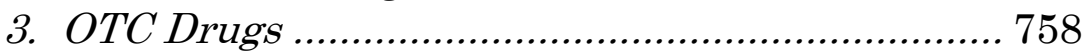

4. Other Considerations........................................... 761

V. RECOMMENDATIONS FOR PROVIDERS AND SYSTEMS ....... 763

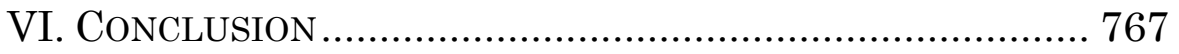

* Associate Professor Clinical Psychiatry, Division of Forensic Psychiatry, Department of Psychiatry, Indiana University School of Medicine. Adjunct Professor of Law, Indiana University McKinney School of Law. The author wishes to thank Alexia Torke, MD, PhD and Nicolas Terry, LLM for valuable comments on an earlier draft of this manuscript. 


\section{INTRODUCTION}

Cosmetic neurocognitive enhancement is the use of prescription stimulant drugs to enhance cognitive functions such as attention, concentration, and memory beyond normal limits in healthy people. ${ }^{1}$ Interest in cosmetic neurocognitive enhancement has grown as treatments to improve cognition in individuals who suffer from illnesses that impact cognition have become more prevalent, safe, and effective. ${ }^{2}$ Painted partly as self-improvement and partly as disease prevention, the idea that a person could be better than well by chemically manipulating the brain captivates the imagination. ${ }^{3}$ Also sometimes called brain doping, ${ }^{4}$ cosmetic prescribing, or wish-fulfilling medicine, the prescription medications most commonly requested for cosmetic purposes are stimulant medications regulated as Schedule II controlled substances such as methylphenidate (e.g. Ritalin and Concerta) and dextroamphetamine (e.g. Adderall and the prodrug Vyvanse). 5

1 Tsee Leng Choya, Cognitive-enhancing Drugs in the Healthy Population: Fundamental Drawbacks and Researcher Roles, 2 COGENT PSYCHOL. 1 (Feb. 2015), available at http://www.tandfonline.com/ doi/pdf/10.1080/23311908.2015.1011579.

2 Anjan Chatterjee, Cosmetic Neurology and Cosmetic Surgery: Parallels, Predictions, and Challenges, 16 CAmbridge Q. HealthCARE ETHICS 129 (2007), available at http://ccn.upenn.edu/chatterjee/ anjan_pdfs/CosmeticNeuro_surgeCHQE2007.pdf [hereinafter Chatterjee, Cosmetic Neurology].

3 Davi Johnson Thornton, Brain Culture: Neuroscience And Popular MEDia (2011).

4 Brendan Maher, Poll Results: Look Who's Doping, NATuRe (Apr. 10, 2008), http://www.nature.com/news/2008/080409/full/452674a.html; Regula Ott et al., Neuroenhancement - Perspectives of Swiss Psychiatrists and General Providers, 142 Swiss MED WKLy. 1 (Nov. 27, 2012).

5 Scott Ewing \& Jerrold Rosenbaum, Phrenotropics: Make Up for the Mind, 2 Harvard Rev. Psychiatry 49 (1994); Anjan Chatterjee, Cosmetic Neurology: The Controversy Over Enhancing Movement, Mentation, and Mood, 63 NEUROLOGY 968 (2004) [hereinafter Chatterjee, Controversy]; Anjan Chatterjee, The Promise and Predicament of Cosmetic Neurology, 32 J. MED. ETHICS 110 (2006) [hereinafter Chatterjee, Promise and Predicament]; Eva Asscher et al., 
The place of cosmetic neurocognitive enhancement in health care is controversial. Traditional definitions of health care stress the goals of diagnosis and treatment of the ill. Using this definition, cosmetic neurocognitive enhancement would not be considered health care because the requestor is not ill or disabled. However, the World Health Organization (WHO) has much broader definitions of health and health care ${ }^{6}$ that would easily encompass the practice of cosmetic neurocognitive enhancement if the practice may be defined as the prescription of medication for promotion, maintenance, or restoration of the mental or social well being of the individual.

Similar to professional opinion, popular opinion is divided on the legitimacy of both the request for cosmetic neurocognitive enhancement and the provider response to the request. Some seekers of cosmetic neurocognitive enhancement are "early adopters" of a "successful" technology, ${ }^{7}$ and portrayed as earnest students trying to weather an educational system that does not meet their individual learning needs. ${ }^{8}$ A slightly less complimentary term, requestors of neurocognitive enhancement are sometimes referred to as "non-medical" users of highly regulated controlled substances. At the most pejorative end of the spectrum, some authors characterize all users of stimulants for cosmetic neurocognitive enhancement as addicted to the substances and/or guilty of "cheating."

Wish-Fulfilling Medicine in Practice: A Qualitative Study of Physician Arguments, 38 J MED. ETHICs 327 (2012).

${ }^{6}$ Health is "The state of complete physical, mental, and social wellbeing and not merely the absence of disease or infirmity" and health care is "services provided to individuals or communities by health service providers for the purpose of promoting, maintaining, monitoring or restoring health." WHO Centre for Health Development, A Glossary of Terms for Community Health Care and Services for Older Persons, 5 AGEING AND HEALTH TECHNICAL REPORT (2004), available at http://www.who.int/kobe_centre/ageing/ahp_vol5_glossary.pdf.

7 See, e.g., Henry Greely et al., Towards Responsible Use of Cognitive-Enhancing Drugs by the Healthy, 456 NATURE 702 (2008).

8 Nuffield Counsel on Bioethics, Novel Neurotechnologies: INTERVENING IN THE BRAIN 162-91 (Nuffield Counsel on Bioethics ed., 2013), available at http://nuffieldbioethics.org/wp-content/uploads/ 2013/06/Novel_neurotechnologies_report_PDF_web_0.pdf. 
Providers are also portrayed at the extremes in the popular media. Providers who do not offer or provide cosmetic neurocognitive enhancement seem unfeeling, egotistical, paternalistic, and rigid. When providers do prescribe medications for cosmetic enhancement purposes (i.e. without clear evidence of illness), commentators characterize them as pawns of drug companies, medicalizing the human plight, ignorant of side effect, overly idealistic about benefits of drugs, and/or contributing to the problems of drug addiction and diversion.

In the sections that follow, I argue that the definition and scope of health care allows for the practice of cosmetic neurocognitive enhancement, that there is great variability in the population defined as well, and that sufficient indeterminacy exists so that a more nuanced view of cosmetic neurocognitive enhancement is necessary to inform policy and practice. Such a view respects the autonomy of both providers and patients, while balancing provider responsibilities such as beneficence, non-maleficence, and social justice. I then review drivers of patient requests for enhancement and physician experience with requests prior to concluding with a model practice guideline. I constrain the discussion to currently available medication because the assessment of risks and benefits of medication should be driven by the best empiric evidence available. ${ }^{9}$

\section{NEUROCOGNITIVE ENHANCEMENT IN HEALTH CARE}

Although some definitions of health care revolve around the prevention and treatment of disease, ${ }^{10}$ the WHO takes a broader view of health, equating it with optimal well-

9 A similar argument is made by Smith and Farah. M. Elizabeth Smith \& Martha J. Farah, Are Prescription Stimulants "Smart Pills"? The Epidemiology and Cognitive Neuroscience of Prescription Stimulant Use by Normal Healthy Individuals, 137(5) PsYCHOL. Bull. 717 (2011).

10 See, e.g., Health, MERRIAM-WEBSTER DiCTIONARY, http://www.merriam-webster.com/dictionary/health (last visited Feb. 13, 2015); Francis Fukuyama, Our Posthuman Future: Consequences of the Biotechnology Revolution 206 (Picador ed., 1st ed. 2002) ("The original purpose of medicine is, after all, to heal the sick, not turn healthy people into gods."). 
being. 11 With only $17 \%$ of individuals functioning optimally, ${ }^{12}$ health care activities are applicable to $83 \%$ of the population. In addition to the correction of abnormal bodily function to relieve symptoms, mental, emotional, and social factors are all considered equally important in this definition. Other definitions of health emphasize the capacity of the individual to self-manage and adapt to the environment. 13 Cosmetic neurocognitive enhancement represents one way in which an otherwise well individual may choose to adapt to a challenging environment through the use of the services of a health care provider. From an ethical perspective, utility arguments favor cosmetic practices, ${ }^{14}$ placing high value on the self-maintenance of health, enhancement of self-esteem, and improved social functioning as potential goods meriting inclusion of cosmetic enhancement as a health care activity.

From a practical standpoint, the care of the well is far from remote to the practice of health care. Medical providers hear patient requests for enhancement in consultation rooms across the United States every day with over half of providers receiving monthly requests for enhancement and more than $10 \%$ receiving daily enhancement requests. ${ }^{15}$ In addition to hearing requests for enhancements, providers offer enhancements to patients. Approximately one third of providers offer enhancements to patients on at least a monthly basis and over $7 \%$ offer enhancements to patients on a daily basis. ${ }^{16}$

11 World Health ORG., Basic Documents 1 (World Health Organization ed., 48th ed. 2014), available at http://apps.who.int/gb/bd/.

12 U.S. DeP't of Health and Human Servis., Mental Health: A REPORT OF THE SuRgeon General (Howard H. Goldman et al. eds., 1999), available at http://profiles.nlm.nih.gov/ps/retrieve/ ResourceMetadata/NNBBHS.

13 Machteld Huber et al., How Should We Define Health?, BMJ (July 26, 2011), http://www.bmj.com/content/343/bmj.d4163.

14 Chatterjee, Cosmetic Neurology, supra note 2, at 129-37.

15 Timothy D. Hotze et al., "Doctor, Would You Prescribe a Pill to Help Me ... ?" A National Survey of Physicians on Using Medicine for Human Enhancement, 11 AM. J. Bioethics 3-13 (2011) [hereinafter Hotze et al., Doctor].

16 Id. 
Cosmetic surgery is an example of health care offered to the well for the purpose of enhancement. Both cosmetic neurocognitive enhancement and cosmetic surgery alter the body of someone without known illness, despite risk of significant side effects. ${ }^{17}$ Both have personal satisfaction as an unclear and difficult-to-measure endpoint. And both involve the use of limited resources for cosmetic enhancement despite significant ongoing need for restorative and rehabilitative services. ${ }^{18}$ When effective, both processes tend to confer social advantage and thus potentially widen the gap between the enhanced and unenhanced. Similar to cosmetic surgery, third party payment for cosmetic neurocognitive enhancement is unlikely, so the resource is limited to individuals able to pay for it.

In some ways, however, the practice of cosmetic neurocognitive enhancement is more complicated and less certain than physical enhancement. Individuals requesting cosmetic neurocognitive enhancement are likely to feel stressed and dysphoric at the time of presentation, ${ }^{19}$ which is a well-known risk factor for poor outcomes following cosmetic procedures. In contrast, individuals usually deemed candidates for cosmetic procedures are "healthy individuals with a positive outlook and realistic expectations." 20 Other people at risk for a poor outcome following a cosmetic procedure include those with unrealistic expectations of the intervention, who view altering the body as "fixing" a life problem. In the case of neurocognitive enhancement, all requests involve a perceived need by the requestor to "fix" a mismatch between the cognitive demands imposed by the environment and the

17 Cosmetic surgery is the reshaping "of normal structures of the body in order to improve appearance and self-esteem." Cosmetic Procedures, AM. SOC'Y PLASTIC SURGEONS, http://www.plasticsurgery.org /cosmetic-procedures.html, archived at http://perma.cc/N8ZD-GQE2 (last visited May 20, 2015).

18 Chatterjee, Cosmetic Neurology, supra note 2, at 129-37.

19 Genevieve Verdi et al., Non-Medical Prescription Stimulant Use in Graduate Students Relationship With Academic Self-Efficacy and Psychological Variables, J. ATTENTION DisORDERs (Apr. 22, 2014).

20 Cosmetic Procedures, supra note 14. 
resources possessed by the individual. Poor outcomes are then more likely because requestors are so focused on the goal that they almost invariably inflate potential benefit and minimize risk. ${ }^{21}$

The effectiveness of most cosmetic surgery is measurable in physical and objective terms, while satisfaction with that change is more subjective. However, the effectiveness of cosmetic neurocognitive enhancement is only measured by subjective impressions of changes in cognition and the associated sense of satisfaction, all which is highly subjective and reliant upon the mood of the person evaluating the past experience at the time the person is asked to reflect on it.

While most cosmetic surgery involves a one-time procedure of greater risk than taking a prescribed stimulant as directed, cosmetic neurocognitive enhancement involves chronic treatment with drugs with unclear chronic effects. The brain is the most poorly understood organ in the body and brain pathways are highly interconnected so unintended effects may occur in an unpredictable fashion. Stimulants intended to improve cognition, for example, may also induce mood changes, irritability, anxiety, impulsivity and problems with reality testing. In addition to the direct risks of the individual medications, altering the brain likely also impacts the person's perception of self, others, and the intervention. At the extreme, the substance may potentiate vulnerability for addiction in the user such that the user values drug effects over social and occupational activities and relationships.

Strategies to optimize response and reduce risk at the individual level are equally relevant for cosmetic surgery and cosmetic neurocognitive enhancement. These include setting stable healthy habits as a precondition of cosmetic treatment, treating diagnosable conditions before moving to cosmetic enhancements, ensuring sufficient resources to maximize compliance with recommendations, and requiring financial accountability.

21 See, e.g., Alan D. Desantis \& Audrey Curtis Hane, "Adderall is Definitely Not a Drug": Justifications for the Illegal Use of ADHD Stimulants, 45 Substance Use \& Misuse 31 (2010). 
At the societal level, cosmetic neurocognitive enhancement clearly poses more challenges than cosmetic surgery. Prescription drug abuse is a major public health problem and problematic use of stimulants is rising in all adult populations. ${ }^{22}$ Personal misuse of medications may result in increased health care utilization and cost due to accidents and other complications in the individual who escalates dose and uses prescribed stimulants with other substances. Harm to others may occur when the individual does not properly store or dispose of medications, or diverts them to individuals to whom they were not prescribed. Sixty-one percent of college students diagnosed with attention deficit hyperactivity disorder (ADHD), a condition typically treated with prescribed stimulant medications, reported diverting stimulant medications. ${ }^{23}$ Diversion may be more common in non-medical users of stimulant medications who require low doses on an intermittent basis in order to achieve the desired effects. ${ }^{24}$

While the diversion of stimulant medications in the United States is a problem, the United States is by far the leading supplier of stimulants worldwide and it is unlikely that the global amphetamine issue can be addressed while stimulant production and consumption is increasing. ${ }^{25} \mathrm{Up}$ to $90 \%$ of the amphetamines sold through illicit means for recreational use are products of U.S. pharmaceutical firms,

22 Steven M. Berman et al., Potential Adverse Effects of Amphetamine Treatment on Brain and Behavior: A Review, 14 MOLECULAR PsYCHIATRY 123 (2009).

23 Laura M. Garnier et al., Sharing and Selling of Prescription Medications in a College Student Sample, 71 J. CliniCAL Psychiatry 262 (2010).

24 Alan D. Desantis et al., Illegal College ADHD Stimulant Distributors: Characteristics and Potential Areas of Intervention, 48 Substance Use \& Misuse 446 (2013).

25 Nicolas Rasmussen, America's First Amphetamine Epidemic 1929-1971: A Quantitative and Qualitative Retrospective With Implications for the Present, 98 AM. J. PuB. HEALTH 974 (2008). "Any effort to deal harshly with methamphetamine users today in the name of epidemic control, without touching medical stimulant production and prescription, is as impossible practically as in 1970-and given historical experience, even more hypocritical." Id. 
and half of the nation's illicit stimulant users consume pharmaceutical amphetamines only. ${ }^{26}$

Although amphetamines were over the counter medications (OTCs) for forty years, and have been increasingly popular prescribed drugs, recognition of harms to public health resulted in an international resolution calling for the development of less risky substances capable of producing the same therapeutic benefit. 27 Manufacturers have made progress in producing less divertible alternative forms of stimulant medications such as patches and longacting formulations, an effective stimulant medication without some addiction liability does not yet exist. It is therefore incumbent on the provider to use the lowest possible dose, for the shortest possible time, with regular follow-up for the duration of medication provision to mitigate both individual and societal harm.

\section{REQUESTS}

The drives for wellness and enhancement are not new. ${ }^{28}$ Human beings have attempted to improve and adapt for centuries. In this section I explore some of the recent drivers for requests for cosmetic neurocognitive enhancement and the expectations of requestors.

\section{A. Neuromyths Facilitating Requests}

There are a number of myths about brain structure and function that facilitate undue faith in cosmetic

26 Shaheen E. Lakhan \& Annette Kirchgessner, Prescription Stimulants in Individuals With and Without Attention Deficit Hyperactivity Disorder: Misuse, Cognitive Impact, and Adverse Effects, 2 BRAIN AND BEHAV. 661 (2012).

27 U.N. Convention on Psychotropic Substances, Vienna, Jan. 11Feb. 21, 1971, Resolutions Adopted by the United Nations Conference for the Adoption of a Convention on Psychotropic Substances, available at http://www.unodc.org/pdf/convention_1971_en.pdf.

28 See, e.g., Wayne Hall, Feeling 'Better Than Well', 5 EMBO REP. 1105-1109 (2004). 
neurocognitive enhancement. ${ }^{29}$ People believe that intelligence is innate and immutable; 30 consequently, if they evaluate their own performances as suboptimal they use stimulants in the service of changing their destinies. Of those who consider that the brain is changeable, many people believe that the brain is a muscle, and that thinking builds brain cells so, the mythical analogy goes, thinking "more" or "faster" must somehow be good for the brain like aerobic exercise is good for the body.

Then, there is the popular culture belief that the brain is full of unused circuits and that our minds are limitless if we can but access the usually inaccessible areas. ${ }^{31}$ In addition to the neuromyths mentioned above that are conducive to efficacy beliefs, other neuromyths cause people to minimize risk. Some neuromyths, for example, posit that the brain is modular, like a computer, leading people to believe that it is possible to affect one aspect of brain function without affecting others.

Add to this intuitive appeal the increasing reports in the media that stimulant medications are safe ${ }^{32}$ and effective in enhancing complex problem solving and overall cognition, ${ }^{33}$ the increase in demand and use is not surprising. A task for the provider is to identify and correct these misperceptions

29 See generally Tracy D. Gunter, Can We Trust Consumers With Their Brains? Popular Cognitive Neuroscience, Brain Images, Self-Help and the Consumer, 11 InD. HEALth L. REV. 483, 509-10 (2014).

30 Male students believed taking performance-enhancing drugs for sports is more unethical than using stimulants to improve grades because of this belief that intelligence is innate. Tonya Dodge et al., Judging Cheaters: IS Substance Abuse Viewed Similarly in the Athletic and Academic Domain?, 26 Psychol. AdDictive BeHAV. 678, 680 (2012), available at www.apa.org/pubs/journals/releases/adb-ofp-dodge.pdf.

31 Id.; LUCY (EuropaCorp 2014) (film concluding that using $100 \%$ of the brain's capacity freed the protagonist from the continuum of space and time); Limitless (Relativity Media 2011) (film about a writer using an experimental medication with the by line "Accessing $100 \%$ of your brain is now possible with....")

32 How Do Stimulants Affect the Brain and Body, NAT'L Inst. ON DRUG ABUSE, (Nov. 2014), http://www.drugabuse.gov/publications/ research-reports/prescription-drugs/stimulants/how-do-stimulantsaffect-brain-body, archived at http://perma.cc/2CEA-XUAE.

33 Desantis \& Hane, supra note 21. 
in individuals requesting cosmetic neurocognitive enhancement.

\section{B. Direct-to-Consumer Advertising as a Driver of Patient Requests}

Contributing to neuromyths in popular culture that would make cosmetic neurocognitive enhancement desirable and seemingly attainable, the products used are also familiar to people due to the increasing frequency with which stimulants have been prescribed in recent years. There is not doubt that DTCA increases the number of requests for medications that patients bring to their providers and no doubt that the practice results in more prescriptions being written by providers. As the result of successful awareness campaigns and marketing, the use of prescription of stimulants increased exponentially and that increase is associated with increased non-medical use. ${ }^{34}$

Amphetamines and other stimulant drugs have been used for more than 100 years for the treatment of impaired alertness, attention, and concentration. The products were first sold as OTC elixirs, and later as prescription products. Beginning twenty to thirty years ago, the regulatory environment became favorable for direct-to-consumer advertising (DTCA) of prescription products by pharmaceutical companies that, prior to that time, directed most advertising to prescribing providers. In 1999 the pharmaceutical industry launched the first DTCA campaign for stimulant drugs to treat children and other stimulant manufacturers followed suit in the two years that followed. The advertisements were typically lifestyle-based advertisements portraying ideal family life with the inference that such was possible if the parent treated the child's behavioral problems with prescribed substance. Soon thereafter the market became increasingly competitive with more companies and claims entering the market place.

34 S.E. McCabe et al., Trends in Medical Use, Diversion, and Nonmedical Use of Prescription Medications among College Students from 2003 to 2013: Connecting the Dots, 39 ADDICTIVE BEHAVIORS 1176 (2014). 
In addition to raising awareness of treatable conditions, advertisements sometimes blur the boundaries between symptoms of normal function and those indicative of illness or disease, by emphasizing convenience, minimizing risk, overstating efficacy, and broadening indications, despite significant regulatory prohibitions. ${ }^{35}$ It was not until 2006 that the FDA ordered a black box warning placed on stimulants for cardiovascular risk. This act quelled the DTCA of stimulants to some extent. By this time, however, the influence of the advertising in the marketplace had already been felt.

Importantly, the Food and Drug Administration (FDA) cannot require drug companies to submit advertisements for approval prior to marketing. As a result, members of the public may see advertisements that violate regulatory standards for variable periods of time prior to FDA review. During this interval, the individual viewing the advertisement will have no assistance in deducing whether the advertisement includes false or misleading information. 36 Once a deceptive advertisement is discovered, the FDA is empowered to send a letter to the manufacturer requesting that the company remove the advertisement or publish a corrective advertisement. In more egregious cases, the FDA has the discretion to issue warning letters, seek an injunction, or bring criminal action against a pharmaceutical company. These actions, however, take time and there is also no particular requirement that the retraction or correction be displayed as prominently as the misleading advertisement. By the time the FDA acts, much harm has potentially been done.

35 U.S. DEP'T. OF HEALTh \& HUMAN SERVS. GUIDANCE FOR INDUSTRY InTERNET/SOCIAL MEDIA PlatForms WITH CHARACTER SPACE Limitations - PRESENTING Risk AND BenEFit InFormation FOR Prescription Drugs and Medical Devices, (June 2014), available at http://www.fda.gov/downloads/drugs/guidancecomplianceregulatoryinfor mation/guidances/ucm401087.pdf.

36 See generally Prescription Drug Advertising: Questions and Answers, U.S. FOOD \& DRUG ADMIN. http://www.fda.gov/Drugs/ ResourcesForYou/Consumers/PrescriptionDrugAdvertising

/UCM076768 (last updated Sept. 13, 2012) (answering common questions from consumers regarding direct-to-consumer advertising). 
As noted by Singh, "The journey of stimulant drug advertising into the public domain has taken the claims of the drug maker from [symptomatic] control, to a blurring of control to normalization, to a clear vision of enhancement." 37 Now that vision is a reality and the de facto gatekeeper has become the provider.

\section{So What Is It That People Do (and Do Not) Want To Alter?}

In the realm of cosmetic neurocognitive enhancement, people frequently cite goals of performing tasks better, working harder and optimizing personal achievement. Though people seeking stimulant medications believe that enhancing attention, concentration and task persistence will lead inevitably to these goals, this is not necessarily the case. 38 Some users believe that they suffer from undiagnosed ADHD and seek stimulants as the appropriate treatment for their self-diagnosed disorder outside a formal medical evaluation. ${ }^{39}$ Others believe that because the primary motivation to use stimulants on a cosmetic basis is noble (i.e. to excel and assist others in excelling in the case of distribution) the use is more appropriate than in circumstances in which the primary motivation is to become intoxicated or euphoric. ${ }^{40}$

Individuals requesting cosmetic neurocognitive enhancement generally emphasize autonomy and choice in making decisions about cosmetic neurocognitive enhancement, uniformly rejecting notions of compulsory use. ${ }^{41}$ Users prefer easily accessible OTC drugs to

37 See Ilina Singh, Not Just Naughty: 50 Years of Stimulant Drug Advertising, in MEDICATING Modern AMERICA: PRESCRIPTION DRUGS IN HISTORY 131 (Andrea Tone \& Elizabeth Siegel Watkins eds, 2007).

38 Richard J. Haier, Increased Intelligence is a Myth (So Far), Frontiers Syss. Neuroscience (Mar. 12, 2014), http://journal.frontiersin.org/Journal/10.3389/fnsys.2014.00034/full, archived at http://perma.cc/AY24-Y854.

39 Desantis \& Hane, supra note 21.

40 Id.

41 Sebastian Sattler et al., Impact of Contextual Factors and Substance Characteristics on Perspectives toward Cognitive 
prescription drugs. Seekers of cosmetic neurocognitive enhancement favor medications of low risk and low cost, tolerating relatively few uncomfortable side effects and no serious side effects. ${ }^{42}$ Yet, many users of neurocognitive enhancers underestimate the risks involved in pharmaceuticals because they come through the medical establishment. ${ }^{43}$

Individuals pursuing neurocognitive enhancement are generally not interested in altering traits they view as identifying or core personality characteristics such as mood and self-control as either direct effects or side effects of neurocognitive enhancement. ${ }^{44}$ The reality, however, of brain manipulation is that changing one aspect of experience will doubtless change other aspects because the brain has a relatively small number of pathways that are used in different ways at different times for different things. The enterprise of cosmetic neurocognitive enhancement is all about trade offs, and owing to the biological reality of the connectome, will likely remain so for the foreseeable future. ${ }^{45}$ For some users the trade off may be more

Enhancement, 8 PLoS ONE e71452 (2013).

42 Id.; See also Kimberly J. Schelle et al., Attitudes Toward Pharmacological Cognitive Enhancement- $A$ Review, 8 FrontiERs IN SYSTEMS NEUROSCIENCE (2014).

43 See, e.g., Alan Schwartz, Drowned in a Stream of Prescriptions, N.Y. Times, Feb. 3, 2013, at A1.

44 Laura Y. Cabrera et al., Reasons for Comfort and Discomfort with Pharmacological Enhancement of Cognitive, Affective, and Social Domains, Neuroethics (2014); Schelle et al., supra note 43; Cynthia Forlini \& Eric Racine, Added Stakeholders, Added Value(s) to the Cognitive Enhancement Debate: Are Academic Discourse and Professional Policies Sidestepping Values of Stakeholders? 3 AJOB PRIMARY RES. 33 (2012) [hereinafter Forlini, Added Stakeholders]; Philip Brey, Human Enhancement and Personal Identity, in NeW Waves In Philosophy of Technology 169 (Jan Kyrre Berg Olsen Friis et al. eds., 2009).

45 Thomas Hills \& Ralph Hertwig, Why Aren't We Smarter Already: Evolutionary Trade-Offs and Cognitive Enhancements, 20 CURRENT DiRECTIONS PsYCHOL. SCI. 373 (2011). 
favorable than for others, but users must understand there will be a trade off. 46

Attempts to distinguish cosmetic neurocognitive enhancement from substance misuse or addiction have largely demonstrated more similarities among, than differences between, stimulant users identifying academic goals and those espousing recreational goals for their use. ${ }^{47}$ From a personality perspective, users of stimulants for cosmetic neurocognitive enhancement were more impulsive, less prosocial, less empathic, and more strategic and instrumental in their approach to life circumstances compared to individuals that did not use stimulants. ${ }^{48}$ Those using cosmetic neurocognitive enhancement were more likely to associate stimulant use with recreation, report exaggerated well being, ${ }^{49}$ abuse other substances (e.g. alcohol, marijuana, cocaine, ecstasy), and engage in risky activities. 50 Users of cosmetic neurocognitive enhancement failed to achieve objective long-term academic benefit despite report of short-term gains in self-perceived

${ }^{46}$ Hannah Maslen et al., Pharmacological Cognitive EnhancementHow Neuroscientific Research Could Advance Ethical Debate, 8 FRONTIERS Sys. NEUROSCIENCE 107 (2014).

47 See Eric Racine \& Cynthia Forlini, Cognitive Enhancement, Lifestyle Choice or Misuse of Prescription Drugs?, 3 Neuroethics 1 (2008) (providing a review of this topic) [hereinafter Racine, Cognitive Enhancement; Amelia M. Arria \& Robert L. DuPont, Nonmedical Prescription Stimulant Use among College Students: Why We Need To Do Something and What We Need To Do, 29 Journal OF ADDICTIVE DisEASEs 417 (2010); Matthias Vonmoos et al., Differences in SelfReported and Behavioral Measures of Impulsivity in Recreational and Dependent Cocaine Users 133 Drug Alcohol DePendence 61 (2013); Marissa J. Maier, Pharmacological Cognitive Enhancement in Healthy Individuals: A Compensation for Cognitive Deficits or a Question of Personality? 10 PLoS ONE e0129805 (2015).

48 Maier, supra note 48.

49 Cynthia M. Hartung et al., Stimulant Medication Use in College Students: Comparison of Appropriate Users, Misusers, and Nonusers, 27 PsYchol. AdDICTIVE BEHAVs. 832 (2013).

50 Shaheen E. Lakhan \& Annette Kirchgessner, Prescription Stimulants in Individuals With and Without Attention Deficit Hyperactivity Disorder: Misuse, Cognitive Impact, and Adverse Effects, 2 BRAIN \& BEHAV. 661 (2012); Hartung et al., supra note 50. 
cognitive ability, ${ }^{51}$ regardless of whether the individual is identified as healthy or as an individual affected by ADHD. 52 It may well be that stimulants exert their primary enhancement effects on the emotions of users, as opposed to the cognition of users. ${ }^{53}$ The moniker of "smart drug" may in fact conceal the degree to which the alteration sought is a mood alteration clothed in the language of intellect and achievement.

Purposeful deception of physicians to obtain prescription stimulants may be more common than generally believed, 54 but continues to represent a minority of interactions with providers. ${ }^{55}$ Users of stimulants for cosmetic neurocognitive enhancement are more likely to have antisocial features, which may increase the risk for purposeful deception of others. 56 Particularly among young adults, males, and individuals at the low and high extremes of income were more likely to report attempts to deceive physicians, as were young people who reported abusing recreational substances and those identified as lesbian-gay-bisexualtransgendered. ${ }^{57}$ Several commentators have observed that prescribers are particularly easy to deceive, 58 and symptoms of disorders for which stimulants are prescribed are easy to feign. 59 The tactics identified by individuals deceiving

51 Hartung et al., supra note 50.

52 Claire Advokat \& Mindy Scheithauer, Attention-Deficit Hyperactivity Disorder (ADHD) Stimulant Medications as Cognitive Enhancers, FrontiERs NeURoscience (May 29, 2013), http://journal.frontiersin.org/article/10.3389/fnins.2013.00082/full.

53 Scott Vrecko, Just How Cognitive Is "Cognitive Enhancement"? On the Significance of Emotions in University Students' Experiences with Study Drugs, 4 AJOB NEURosciencE 4 (2013) [hereinafter Vrecko, Just How Cognitive].

54 John M. Stogner et al., Deception for Drugs: Self-Reported "Doctor Shopping" Among Young Adults, 27 J. AM. BoARD FAM. MED. 583 (2014).

55 Id.

56 Maier, supra note 48.

57 Stogner et al., supra note 55.

58 Schwartz, supra note 44; Trent Wolbe, How I Hacked My Brain With Adderall: A Cautionary Tale, THE VERGE (July 26, 2012, 10:38 AM), http://www.theverge.com/2012/7/26/3184496/hacked-brainadderall-cautionary-tale, archived at http://perma.cc/AJ6X-N2AA.

59 Will Oresmus, The New Stimulus Package, SlATE (2013) 
clinicians include memorizing symptoms of ADHD and responding in deceptive ways on ADHD screening questions, writing things on their hands or displaying other signs of disorganization characteristic of ADHD, and complaining of improving but persistent symptoms to accomplish dose escalation that would lead to a sufficient supply of stimulant for the index "patient" and those to whom he or she may divert it. 60

\section{RESPONSES: PROVIDER ISSUES}

Providers have varying levels of comfort with patient requests for enhancement and respond to these requests in a variety ways. Many providers grant requests for enhancement and offer patients enhancements, though there is a significant minority that rejects enhancement of any kind as outside the practice of medicine. ${ }^{61}$ In addition to concerns about legitimacy of enhancement in health care and the goals of the doctor-patient relationship, safety, social factors, and patient-specific factors contributed to provider ambivalence. ${ }^{62}$

http://www.slate.com/articles/technology/superman/2013/03/adderall_rit alin_vyvanse_do_smart_pills_work_if_you_don_t_have_adhd.html; Randy A. Sansone \& Lori A. Sansone, Faking Attention Deficit Hyperactivity Disorder, 8 InNovations in CliniCAL NeURoscience 10 (2011).

60 Scott Vrecko, Everyday Drug Diversions: A Qualitative Study of the Illicit Exchange and Non-Medical Use of Prescription Stimulants on a University Campus, 131 Soc. SCI. \& MED. 297 (2015) [hereinafter Vrecko, Everyday Drug Diversions].

61 Timothy D. Hotze et al., Response to Open Peer Commentaries on “Doctor, Would You Prescribe a Pill to Help Me...?' A National Survey of Physicians on Using Medicine for Enhancement," 11 AM. J. Bioethics W1 (2011) [hereinafter Hotze et al., Response].

62 Cynthia Forlini \& Eric Racine, Considering the Causes and Implications of Ambivalence in Using Medicine for Enhancement, 11 AM. J. BIoEthics 15 (2011) [hereinafter Forlini, Considering the Causes]. 


\section{A. Models of Provider-Patient Interactions}

How the provider understands the patient relationship is a significant variable in the response to patient requests. The traditional biomedical model is one in which providers rely on paternalism and objective data to guide their interactions with ill patients. In this model, the responsibilities for diagnosis, treatment selection, treatment monitoring, and treatment goals all reside with the beneficent professional acting in his patient's best interest. The patient, in this model, offers his symptoms to the provider and accepts the treatment prescribed. The assumption in the biomedical model is that the patient and provider share amelioration of illness as the goal and both provider and patient will place high value on the symptomfree state. The biomedical model frequently works well with older, ill, distressed, and less-educated patients, ${ }^{63}$ pursuing traditional treatments and treatment goals for a mutually identified disease state.

Traditional biomedical providers typically derive authority from the greater biomedical knowledge they possess and place a high level of confidence in evidencebased practices. Evidence-based medicine emphasizes the published literature as the primary source of credible information and authority. ${ }^{64}$ Technical information offered to patients by biomedical providers will be informed by a combination of evidence from the professional literature, professional experience, and personal values. Cosmetic neurocognitive enhancement will succeed in the biomedical model typically used by traditional providers only when evidence from groups of similarly situated subjects demonstrates that there is known and discernible benefit that outweighs known risk. ${ }^{65}$

63 Sara L. Swenson et al., Patient-centered Communication: Do Patients Really Prefer It? 19 J. Gen. InTERnAL MED. 1069 (2004).

64 See, e.g., Laurence Greenhill et al., Practice Parameter for the Use of Stimulant Medications in the Treatment of Children, Adolescents, and Adults, 41 J. Am. ACAD. ChILD \& AdOLESCENT PSYCHIATRY 26S (2 Supp. 2002).

65 Hotze et al., Doctor, supra note 15. 
By contrast, most patients who seek cosmetic neurocognitive enhancement will be demographically different from those who prefer a traditional biomedical approach. Younger, healthier, and more highly educated patients will tend to prefer provider interactions that fall on the spectrum of informed choice 66 and shared decisionmaking models. 67 Although perspectives from traditional biomedical, informed choice and shared decision-making models are not mutually exclusive, they do have different centers of control, rely on different sources of authority, and prioritize different outcomes. 68

In traditional biomedical models, the provider makes the diagnosis, decides on treatment, and gives the patient information on the treatment and its risks, with some acknowledgment of alternatives. In informed choice models, the provider still sets the goals of treatment, but offers information without a specific recommendation to a more active patient considering treatments. In shared decisionmaking models, the provider offers information specific to the patient's stated goals and objectives with as little bias as possible and without any particular recommendation.

In informed choice and shared decision-making models, the provider's goal is to understand the patient's experience, wishes, and needs for the encounter from a broader biopsychosocial perspective, consistent with the definition of health care put forward by the WHO. The provider focuses on the patient's subjective need as the indication for the intervention, without relying on the presence of an illness as the threshold for providing a treatment intervention. The provider using a patient-centered frame of reference will likely be more comfortable with using the patient's opinion of the intervention as a viable justification for the intervention and for the evaluation of the effectiveness of

66 Elizabeth Murray et al., Clinical Decision-Making: Patients' Preferences and Experiences, 65 Patient Educ. \& Counseling 189 (2007).

67 Bernard Lo, Resolving Ethical Dilemmas: A Guide For CliniCians 177-180 (5th ed. 2013).

68 Jozien Bensing, Bridging the Gap. The Separate Worlds of Evidence-Based Medicine and Patient-Centered Medicine, 39 PATIENT EDUC. \& Counseling 17 (2000). 
the intervention. Providers operating in this frame may, for instance, go beyond responding to patient requests for cosmetic enhancement to offering the patient a cosmetic enhancement on a regular basis. ${ }^{69}$

In most studies, patient satisfaction was associated with the more patient-centered approaches to the providerpatient relationship, specifically with provider attention to patient concerns and specific information about patient concerns from the provider. ${ }^{70}$ Although outcomes among satisfied patients are difficult to assess, ${ }^{71}$ compliance with provider recommendations appears highest among satisfied patients. ${ }^{72}$ Discord between provider- and patient-centric models appears greatest when the provider does not value the patient's goal, believe that the available evidence supports the patient's expected benefit, or agree with the patient's assessment of risk. ${ }^{73}$ For providers choosing to offer cosmetic neurocognitive enhancement to their patients, a shared decision-making model is most likely to be constructive in both assessing areas of functional change and in maximizing the compliance necessary to minimize individual and societal risks associated cosmetic neurocognitive enhancement.

69 Hotze et al., Response, supra note 62.

70 Linda C. Zandbelt et al., Satisfaction with the Outpatient Encounter: A Comparison of Patients' and Physicians' Views, 19 J. GEN. INTERNAL MED. 1088 (2004).

71 Joshua J. Fenton, The Cost of Satisfaction: A National Study of Patient Satisfaction, Health Care Utilization, Expenditures, and Mortality, 172 ARCHIVES INTERNAL MED. 405 (2012); Linda Brookes, Patient Satisfaction and Quality of Care: Are They Linked?, Medscape Family Med. (2014).

72 Kelly B. Haskard Zolnierek \& M. Robin Dimatteo, Physician Communication and Patient Adherence to Treatment: A Meta-Analysis, 47 MED. CARE 826 (2009).

73 Tammy C. Hoffmann \& Chris Del Mar, Patients' Expectations of the Benefits and Harms of Treatments, Screening, and Tests: $A$ Systematic Review, 175 JAMA INTERNAL MED. 274 (2015). 


\section{B. Provider Attitudes About Enhancement}

Regardless of orientation of the provider to the providerpatient relationship, providers are generally risk-adverse. ${ }^{74}$ The combination of unclear benefit and significant safety concerns contribute to discomfort in prescribing cosmetic neurocognitive enhancement. ${ }^{75}$ Providers distrust safety claims about stimulants with good reason. Pemoline, for example, was a stimulant medication on the market for twenty-five years before concerns about liver injury became apparent and a black box warning was added to the labeling. It was then removed from the market five years later. ${ }^{76}$ As a second example, the health risks of fenfluramine came to light after twenty-five years of market presence, when combined with phentermine (a stimulant) that had been on the market for almost forty years. Use of the combination product Fen-Phen for rapid weight loss has resulted in billions of dollars in litigation costs, medical surveillance, and damage awards. 77 After experiences such as these, providers will generally favor identifying an existing target symptom or sign of disability to merit the risk of prescribing stimulant medications.

74 Opeyemi C. Banjo et al., Physician Attitudes Towards Pharmacological Cognitive Enhancement: Safety Concerns are Paramount, PLOS ONE (Dec. 14, 2010), http://journals.plos.org/ plosone/article?id=10.1371/journal.pone.0014322.

75 Forlini, Considering the Causes, supra note 63.

76 Information for Healthcare Professionals: Pemoline Tablets and Chewable Tablets (Marketed as Cylert), Food \& Drug Admin. (Oct. 2005), http://www.fda.gov/Drugs/DrugSafety/PostmarketDrugSafety InformationforPatientsandProviders/ucm126461.htm, archived at http://perma.cc/R662-66ZC.

77 See E. Colman, Anorectics on Trial: A Half Century of Federal Regulation of Prescription Appetite Suppressants, 143 ANN. INTERN. MED. 380 (2005); \$3.75 Billion Fen-Phen Settlement Now Final, Associated Press, Jan. 11, 2002; Jef Feeley, Pfizer Asks End to FenPhen Suits Linked to Lung Ailment, Bloomberg News (Aug. 23, 2012); Food AND DRug Admin., FDA ANNOUNCES WithdraWAL FENFLURAMine and Dexfenfluramine (Fen-Phen) (1997); Food and Drug Admin., QUESTIONS AND ANSWERS ABOUT WiTHDRAWAL OF FENFLURAMINE (Pondimine) ANd DeXFEnfluRAmine (REDUX) (2005). 
In addition to ambivalence about safety and risk, providers are also ambivalent about access to cosmetic neurocognitive enhancement. Most providers believe that enhancement should be equally available to all people, ${ }^{78}$ yet providers do not believe that third-party payers should cover enhancements. ${ }^{79}$ They tend to view younger patients as not needing stimulant drugs and having sufficient nonpharmacological options for obtaining the same goals. 80 Providers were most comfortable prescribing to older patients to improve overall health, daily living, and support personal efficacy, 81 a finding that is concerning given the rate of misuse among people of advanced age ${ }^{82}$ and the potential for drug interactions in those older adults receiving multiple medications.

When asked directly about enhancement, providers believed that enhancements could help people be happier, and identified subjective suffering, social pressures, and occupational problems as important factors. Higher provider comfort with prescribing enhancement has been

78 See, e.g., Cynthia Forlini \& Eric Racine, Autonomy and Coercion in Academic "Cognitive Enhancement" Using Methylphenidate: Perspectives of Key Stakeholders, 2 Neuroethics 163 (2009) [hereinafter Forlini, Autonomy and Coercion].

79 Hotze et al., Doctor, supra note 15.

80 Banjo et al., supra note 75.

81 Id.

82 See J.W. Culberson et al., Prescription Medication Use Among Self Neglecting Elderly, 22 J. AdDictions Nursing, 63 (2011); Comm. on the Mental Health Workforce for Geriatric Populations, The Mental Health and Substance Use Workforce for Older Adults: In Whose Hands? (Jill Eden et al., eds., NATional ACAdemies Press 2012); Raj K. Kalapatapu \& Maria A. Sullivan, Prescription Use Disorders in Older Adults, 19 AM. J. ADDICTIONS 515 (2010); Jane Carlisle Maxwell, The Prescription Drug Epidemic in the United States: A Perfect Storm, 30 Drug \& AlcoHol ReV. 264 (2011); Laxmaiah Manchikanti, Prescription Drug Abuse: What is Being Done to Address This New Drug Epidemic? Testimony Before the Subcommittee on Criminal Justice, Drug Policy and Human Resources, 9 Pain PHYsician 287 (2006); X. Laqueille et al., Methylphenidate Effective in Treating Amphetamine Abusers with No Other Psychiatric Disorder, 20 Eur. PsYchiatry 456 (2005); Linda Simoni-Wastila \& Huiwen Keri Yank, Psychoactive Drug Abuse in Older Adults, 4 AM. J. GerIATRIC PHARMACOTHERAPY 380 (2006). 
associated with older provider age, male gender, minority race, and high frequencies of patient requests for enhancement. ${ }^{83}$ Recalling that DTCA tends to lead to more requests for medications, and applying now the notion that providers who hear more requests tend to be receptive to granting those requests, the impact of stimulant marketing is felt by both providers as well as patients.

Additionally, some providers will have personal experience with cosmetic neurocognitive enhancement that will likely inform their recommendations to patients. One in five medical students use cosmetic neurocognitive enhancement, 84 and most plan to continue use after graduation. ${ }^{85}$ The predicted continuation is bourn out by studies of practitioners demonstrating that a similar percentage report using stimulants solely for cognitive enhancement on at least one occasion, usually in association with environmental pressures. 86 These personal experiences may facilitate comfort with the practice of cosmetic neurocognitive enhancement.

\section{Availability of Enhancing Drugs (Off-Label Prescribing)}

There are no specific legal or regulatory barriers to the use of prescription drugs for cosmetic neurocognitive enhancement. Although the pharmaceutical industry may only promote and advertise drugs for approved uses, 87

83 See Haier, supra note 39; Stogner, supra note 55.

84 See Jadon Webb et al., Prevalence of Stimulant Use in a Sample of US Medical Students, 25 ANNALs OF CliniCAL Psychiatry 27 (2013); Paul A. Kudlow et al., Cognitive Enhancement in Canadian Medical Students, 45 J. Psychoactive Drugs 360 (2013); Robyn M. Emanuel et al., Cognitive Enhancement Drug Use Among Future Physicians: Findings from a Multi-Institutional Census of Medical Students, 28 J. GEN. INTERNAL MED. 1028 (2013).

85 See John B. Bossaer et al., The Use and Misuse of Prescription Stimulants as "Cognitive Enhancers" by Students at One Academic Health Sciences Center, 88 ACAD. MED. 967 (2013).

86 Andreas G. Franke et al., Use of Illicit and Prescription Drugs for Cognitive or Mood Enhancement Among Surgeons, 11 BMC MED. 102 (2013).

87 I.e., approved uses are recognized by the FDA as the only legitimate intended uses for the purposes of promotion and labeling. 
licensed providers are not constrained from using medications for conditions other than those outlined in the FDA approved uses. ${ }^{88}$ Off-label prescribing is common ${ }^{89}$ and very much in the mainstream of medical practice. ${ }^{90}$ There are, however, some responsibilities incumbent on the provider who undertakes this practice. The provider must base the off-label drug use on sound medical judgment and firm scientific rationale. ${ }^{91}$ The provider must also thoroughly document the intervention, and obtain adequate informed consent. Even with these necessary steps, liability for off-label prescribing is a provider risk worthy of consideration and management through thorough documentation and peer consultation.

Proponents of off-label prescribing typically also favor allowing pharmaceutical companies to detail providers on off-label uses. When looking at established interventions and their indications, the professional literature is adequate to inform the provider. However, when either the drug or the indication is novel, the peer-reviewed literature will be lacking. Presumably the pharmaceutical company that developed a new agent will have the most data about new products and could make high-quality information from preclinical trials available to providers contemplating offlabel use. This would then allow the provider could discharge his above-mentioned responsibility to have thoroughly researched the agent prior to prescribing it. Implicit in this point of view is a high level of confidence in the ability of the provider to differentiate factual

88 Judith Edersheim, Off-Label Prescribing, PsychiATric Times (Apr. 14, 2009), http://www.psychiatrictimes.com/articles/labelprescribing, archived at http://perma.cc/YE4K-WDVW.

89 Id.

90 Stephen M. Stahl, Prescribing Off-Label in Psychopharmacology: IS it the Exception or the Rule?, 1 PsYchED UP 5 (2005).

91 "Off-Label" and Investigational Use of Marketed Drugs, Biologics, and Medical Devices, U.S. FoOD \& DRUG ADMIN., www.fda.gov/regulatoryinformation/guidances/ucm126486.htm, archived at http://perma.cc/98ZW-5RGA (last updated June 25, 2014); Off-Label Use and the Medical Standard of Care, Drug AND DEvicE LAw, (Nov. 2, 2012) http://druganddevicelaw.blogspot.com/2012/11/offlabel-use-and-medical-standard-of.html archived http://perma.cc/49J8-RHCH. 
information from persuasive marketing and this confidence is frequently unmerited. ${ }^{92}$

One possible way to create new sources of information on which providers could rely would be the establishment of efficacy and side-effect reporting schemes for off-label drug uses. This would provide a way for providers using cosmetic neurocognitive enhancement to communicate with one another and standardize some level of peer consultation. It is a potential way to create a source of information to which providers could turn to learn about novel agents, novel uses of established agents, and side effects from prescribed doses. While there are risks such as bias and incorrect inference inherent in this kind of informal research, access to data beyond the provider's individual professional experience could combat arguments that off-label prescribing is uniformly uninformed and wasteful. ${ }^{93}$

\section{Currently Available Enhancing Drugs}

\section{Schedule II Drugs}

The most commonly used (and abused) drugs for neurocognitive enhancement are the Schedule II prescription amphetamines and methylphenidate. Generic names include methylphenidate, desmethylphenidate, detroamphetamine, and lisdexamphetamine. Trade names of some of these drugs include Adderall, Dexedrine, Ritalin, Concerta, Vyvanse, and Focalin. Street names include skittles, smarties, crosses, speed, and uppers. Sometimes

92 A supposition that is not true. Not only are providers influenced by ads, they frequently underestimate the degree to which they are influenced. This literature is reviewed elsewhere.

93 Philip M. Rosoff \& Doriane Lambelet Coleman, The Case for Legal Regulation of Physicians' Off-Label Prescribing, 86 NotRe DaME L. REV. 649, 655 (2011); Madeline J. Cohen, Off-Label: Combating the Dangerous Overprescription of Amphetamines to Children, 82 GEO. WASH. L. REv. 174 (2013); Evelyn Pringle, It's Time to Sue Doctors Who Prescribe Drugs Off-Label Part I, LAWYers AND SETTLEMENTs (Aug. 15, 2007, 12:45 PM), http://www.lawyersandsettlements.com/articles/drugsmedical/off-label-drugs-01288.html archived at http://perma.cc/6THFK4AM. 
these medications are erroneously described as universally effective for adult ADHD and universally enhancing. In fact, the evidence is decidedly more mixed. ${ }^{94}$

Amphetamines and methylphenidate work by prolonging the action of dopamine and norepinephrine, resulting in activation of nerve cells in reward and executive function pathways, with a net result of improving focus, wakefulness, and concentration. Short-term effects of relatively low oral doses include increased energy, alertness, and goal-directed activity, but sometimes come with the cost of increased anxiety and dysphoria with decreased multi-task coordination, cognitive flexibility, selfmonitoring, ${ }^{95}$ and neural plasticity. ${ }^{96}$

Other side effects associated with stimulant use include an unrealistic optimism, inflated sense of well-being, and inflated sense of ability. ${ }^{97}$ Those taking non-medical stimulants perceive themselves as performing significantly better than their peers, despite the objective indicators to the contrary. 98 As dose increases, affirmative risk taking coupled with decreased risk avoidance appears more prominent. For example, drivers under the influence of

94 See, e.g., Samuel Kuperman et al., Bupropion SR vs. Methylphenidate vs. Placebo for Attention Deficit Hyperactivity Disorder in Adults, 13 ANN. OF Clinical Psychiatry 129 (2001); Katherine Sharpe, Medication: The Smart-Pill Oversell, 506 NATURE (2014), available at http://www.nature.com/news/medication-the-smartpill-oversell-1.14701; Katherine Sharpe, Medication: The Smart-Pill Oversell, 506 NATURE (2014), available at http://www.nature.com/news/medication-the-smart-pill-oversell-1.14701 (evidence is mounting that medication for ADHD doesn't make a lasting difference to schoolwork or achievement).

95 Anna-Katherine Brem et al., Is Neuroenhancement by Noninvasive Brain Stimulation a Net Zero-Sum Proposition?, 85 NEURoIMAGE 1058 (2013).

96 Kimberly R. Urban \& Wen-Jun Gao, Performance Enhancement at the Cost of Potential Brain Plasticity: Neural Ramifications of Nootropic Drugs in the Healthy Developing Brain, 8 FronTIERs IN SYS. NEUROSCIENCE 1(2014).

97 Irena P. Ilieva \& Martha J. Farah, Enhancement Stimulants: Perceived Motivational and Cognitive Advantages, 7 FrontiERs IN NEuRoscience (2013), available at http://journal.frontiersin.org/Journal/10.3389/fnins.2013.00198/full.

98 Bossaer, supra note 86. 
stimulants engaged in more speeding, were more impatient, exhibited diminished divided attention, and failed to stop appropriately. ${ }^{99}$

Though these stimulants have complex effects on internal experience and motivation, there is no objective evidence to suggest that critical judgment, wisdom, generalized intelligence, competence, or overall achievement improve when taking stimulants 100 notwithstanding folk psychology and media portrayals. ${ }^{101}$ There is little evidence to suggest that stimulants exert the same effects in individuals of high intelligence and normal cognitive ability than they do in cognitively impaired populations. ${ }^{102}$ In a meta-analysis of studies of methylphenidate, the data "provide no consistent evidence for neuroenhancement effects."103

Turning from efficacy to safety, data suggest that users of cosmetic neurocognitive enhancement reported side of effects during non-medical use of stimulants including anorexia (68.2\% of non-medical users), insomnia (54.5\%), tachycardia (34.1\%), anxiety (15.9\%), tremor (15.9\%),

99 H. Schulze et al., Driving Under the Influence of Drugs, Alcohol and Medicines in Europe-Findings from DRUID Project, EUROPEAN Monitoring CEntre For DRugs and Drug AdDiction (EMCDDA) (2012), www.emcdda.europa.eu/attachements.cfm/att_192773_EN_ TDXA12006ENN.pdf; C. Stough et al., The Effects of MDMA and Methamphetamine on Car Driving Simulator Performance, Cognitive Skills, and Mood States, 4 OPEN ADDICTION JOURNAL 57 (2011).

100 See Fiorlini Racine, Disagreements with Implications: Diverging Discourses on the Ethics of Non-Medical Use of Methylphenidate for Performance Enhancement, 10 BMC MEDICAL ETHICs (2009), available at http://www.biomedcentral.com/1472-6939/10/9.

101 Wolbe, supra note 59; Will Oremus, The New Stimulus Package: Overachievers are Popping Adderall to Get Ahead. Is That a Good Idea?, SlATE, March 27, 2013, http://www.slate.com/articles/technology/ superman/2013/03/adderall_ritalin_vyvanse_do_smart_pills_work_if_yo u_don_t_have_adhd.html, archived at http://perma.cc/AT6U-NDVM.

102 Shaheen E. Lakhan \& Annette Kirchgessner, Prescription Stimulants in Individuals With and Without Attention Deficit Hyperactivity Disorder: Misuse, Cognitive Impact, and Adverse Effects, 2 BRAIN BEHAVIOR 661, 661-667 (2012); Maslen, supra note 47.

103 Dimitris Repantisa et al., Modafinil and Methylphenidate for Neuroenhancement in Healthy Individuals: A Systematic Review, 62 PHARMACOLOGICAL RESEARCH 187-206 (2010). 
headache (13.6\%), and a sense of dependence on the stimulant for concentration (9.1\%). ${ }^{104}$ In addition to these somewhat obvious side effects, non-obvious physical risks such as sudden death and painful sustained penile erection in boys and men have become more frequent as use of Schedule II amphetamine type stimulant medications has increased. 105 Emergency Department (ED) visits and mentions have gone up over time, with stimulant related visits rising by $196 \%$ between 2004 and 2010.106 Of note, the greatest increase in ED mentions involves stimulants among adults. 107 This likely parallels the dramatic rise in the prescription of these drugs to adults. ${ }^{108}$

\section{Schedule IV Drugs}

The wakefulness agents modafinil (Provigil) and armodafinil (Nuvigil) have been used for cosmetic neurocognitive enhancement. Modafinil has some abuse potential, but less than other prescription stimulants. 109

104 Bossaer, supra note 86.

105 FDA Drug Safety Communication: FDA Warns of Rare Risk of Long-Lasting Erections in Males Taking Methylphenidate ADHD Medications and Has Approved Label Changes, FDA (Dec. 17, 2013), $\mathrm{http}: / / \mathrm{www} . f d a . g o v / d r u g s / d r u g s a f e t y / u c m 375796 . h t m \#$, archived at http://perma.cc/A8RV-EU92.

106 Drug Abuse Warning Network, Highlights of the 2010 Drug Abuse Warning Network (DAWN) Findings on Drug-Related Emergency Department Visits, THE DAWN REPORT, http://www.samhsa.gov/data/2k12/DAWN096/SR096EDHighlights2010. $\mathrm{htm}$, archived at http://perma.cc/XTR7-8S8L.

107 Id.

108 Mark Olfson et al., Trends in Office-Based Treatment of Adults With Stimulants in the United States, 74 J. CliniCAL Psychiatry 43 (2013).

109 See FDA Warning Ltr. RE: NDA \#20-717 Provigil (modafinil) Tablets from James R. Rogers (Jan. 14, 2002), www.modafinil.com/fda/, archived at http://perma.cc/9VRY-GEUE; Stefan P. Kruszewski, Euphorigenic and Abusive Properties of Modafinil, Letters to the Editor, 163 Am. J. Psychiatry 549 (2006); FDA, Provigil (modafinil) tablets, Detailed View: Safety Labeling Changes Approved by FDA Center for Drug Evaluation and Research (CDER), http://www.fda.gov/ safety/medwatch/safetyinformation/ucm233612.htm, archived at http://perma.cc/6222-9G9N. 
Although indicated only for sleep disorders and phase shift disorders, modafinil has received attention for increasing use for off-label indications. ${ }^{110}$ Not all studies have demonstrated an effect on cognition ${ }^{111}$ but faster reaction time, 112 improved working memory, more sustained attention, ${ }^{113}$ and improved cognitive flexibility were noted among modafinil subjects when compared to similarly sleepdeprived controls. ${ }^{114}$

Effects of modafinil are also similar to amphetamines in non-sleep deprived individuals, particularly at higher doses. ${ }^{115}$ When compared to amphetamines and caffeine, modafinil exerts similar effects on wakefulness and vigilance, 116 but does not improve complex decisionmaking. ${ }^{117}$ Although individuals with prior drug abuse report feeling intoxicated, non-sleep deprived individuals without a history of substance abuse did not. ${ }^{118}$ In the most recent systematic review and meta-analysis of the available data on modafinil, researchers concluded that the literature supported the idea that modafinil improved attention in

110 Renée A. Peñaloza et al., Trends in On-label and Off-label Modafinil Use in a Nationally Representative Sample, 173 JAMA INTERN MED. 704-06 (2013).

111 Delia C. Randall et al., Modafinil Affects Mood, But Not Cognitive Function, in Healthy Young Volunteers, 18 HuM. PSYCHOPHARMACOLOGY 163, 166-67 (2003).

112 Joseph v. Baranski et al., Effects of Modafinil on Cognitive and Meta-Cognitive Performance, 19 Hum. Psychopharmacology CliniCAL \& EXPERIMENTAL 323, 323-32 (2004).

113 Michelle Gill et al., Cognitive Performance Following Modafinil Versus Placebo in Sleep-Deprived Emergency Physicians: A DoubleBlind Randomized Crossover Study, $158 \quad 13$ Soc'Y FOR ACAD. EMERGENCY MED. 158, 158-65 (2006).

114 Colin Sugden et al., Effect of Pharmacological Enhancement on the Cognitive and Clinical Psychomotor Performance of Sleep-Deprived Doctors: A Randomized Controlled Trial, 255 ANNALS SURGERY 222, 222-27 (2012).

115 Angela P. Makris et al., Behavioral and Subjective Effects of damphetamine and Modafinil in Healthy Adults, 15 ExPERIMENTAL \& CLINICAL PSYCHOPHARMACOLOGY 123, 123-33 (2007).

116 William D. S. Killgore et al., Gambling When Sleep Deprived: Don't Bet on Stimulants, 29 Chronobiology InT'L 43, 43-54 (2012).

117 Id. at 43.

118 Makris et al., supra note 116, at 131. 
non-sleep deprived individuals but was not associated with improvements in other cognitive abilities such as task accuracy and timing. ${ }^{119}$

Although modafinil is a popular study drug in Europe, and has been tested as an alternative to d-amphetamine as a wakefulness-promoting agent, 120 use in the United States may be limited by cost and availability. Although its effects on neural plasticity are unknown, ${ }^{121}$ modafinil does have an advantage over Schedule II amphetamines and methylphenidate in abuse liability. Modafinil is not dissolvable in water and does not remain stable at high temperature, so it cannot be injected or snorted. These features may make it a viable choice for providers engaging in conversations with patients about cosmetic neurocognitive enhancement.

\section{OTC Drugs}

A number of OTC drugs, nutritional supplements, and foods promising cosmetic neurocognitive enhancement are available to consumers on an increasing basis. The OTC drug market is by far the largest drug distribution system in the United States and is steadily growing, providing at least limited access to health care for people who would not otherwise have it. ${ }^{122}$ In addition to traditional OTCs, health care consumers reach for supplements and food products to address cognitive health concerns. Herbal supplements have shown steady growth and sales reached 5.6 billion dollars in 2012. ${ }^{123}$ The global healthy food market is

119 Michael J. Minzenberg \& Cameron S. Carter, Modafinil: $A$ Review of Neurochemical Actions and Effects on Cognition, 33 NEUROPSYCHOPHARMACOLOGY 1477, 1477-1502 (2008).

120 Arthur Estrada et al., Modafinil as a Replacement for Dextroamphetamine for Sustaining Alertness in Military Helicopter Pilots, 83 Aviation, SpaCe \& EnVTL. MED. 556, 556-64 (2012).

121 Urban \& Gao, supra note 97.

122 Consumer Healthcare Products Association, The Value of OTC Medicine to the United States 3 (Jan. 2012), http://www.chpa.org/ValueofOTCMeds2012.aspx.

123 Hank Schultz, Herbal Supplement Sales Rose 5.5\% in US in 2012, ABC Says, NUTRA INGREDIENTS-USA (Aug. 19, 2013), 
growing as well and is predicted to reach one trillion dollars in $2017 .{ }^{124}$

From magic pills and potions, to super foods, these items are advertised as short cuts to the achieving the benefits of exercise, balanced diet, and healthy lifestyle without putting forth the effort to engage in these activities. Information offered about these products in the market place is frequently specious and overblown. Apart from advertisements, frequently disguised as health information, people have little information about effectiveness and risk. 125

Supplements and smart foods are available without consultation with a health care provider and many providers are disinterested in patient use of these compounds because they sometimes erroneously believe the substances to be essentially inert compounds. When compared to modafinil, the herbal agents bacopa and ginseng produced similar effects on wakefulness and a variety of supplements have been associated with liver failure and other significant side effects. ${ }^{126}$

The makers of these products have successfully crafted language to avoid regulation, by emphasizing promotion of wellness versus claims of treating disease. Although there have been calls to hold producers to a higher level of conduct when dealing directly with consumers, there is still little protection for the individual consumer. ${ }^{127}$ Additionally, advertisements for these products are

http://www.nutraingredients-usa.com/Markets/Herbal-supplementsales-rose-5.5-in-US-in-2012-ABC-says, archived at http://perma.cc/22H3-BKRM.

124 Shane Starling, Global Healthy Foods to Hit \$1 Trillion in 2017: Report, NUTRA INGREDIENTS-USA (Nov. 26, 2012), http://www.nutraingredients.com/Consumer-Trends/Global-healthyfoods-to-hit-1-trillion-in-2017-Report, archived at http://perma.cc/U7HLSZWR.

125 For a review see Gunter, supra note 29.

126 Victor J. Navarro et al., Liver Injury from Herbals and Dietary Supplements in the U.S. Drug-Induced Liver Injury Network, 60 HEPATOLOGY 1399 (2014).

127 See generally Denise E. DeLorme et al., The State of Public Research on Over-the-Counter Drug Advertising, 4 INT'L J. Pharmaceutical AND HealthCARE Marketing 208 (2010). 
frequently antagonistic toward pharmaceutical manufacturers, health care providers, and health care systems thus alienating people from the very systems in place to inform and protect them.

Although abuse potential is recognized as a challenge for OTC drugs just as for prescription drugs, ${ }^{128}$ some nonamphetamine stimulant medications continue to be available without a prescription including caffeine, ephedrine, phenylpropanolamine, and pseudoephedrine. Energy drinks and a variety of supplements may combine one or more of these compounds in the same product to improve wakefulness and energy. These combination agents appear to have both effects (i.e. improved vigilance and wakefulness without a concomitant increase problem solving skills or improving complex decision-making) and risks similar to prescribed stimulants. ${ }^{129}$

When taken as a whole, the literature on amphetamines, methylphenidate, modafinil, and OTC stimulants suggest that measurable improvements in cognition are modest, and generally related to increased wakefulness and arousal. Subjective improvements are greater and related to feeling energized, having more motivation, and enjoying tasks more, 130 though these seem to come at the cost of overestimating actual performance on the task in question. Importantly for prescribers of stimulants, non-medical stimulant users tend to use many substances

128 "More than one in ten teens (12\%) report lifetime use of over-thecounter cough or cold medicines to get high." PRESCRIPTION FOR DisAster: How TEENS ABUSE MEDICINE, DEA (2d ed. 2012), available at http://www.justice.gov/dea/pr/multimedia-

library/publications/prescription_for_disaster_english.pdf, archived at http://perma.cc/AC2Z-7LL3. OTC stimulants comprise over half of the OTCs that are abused by teens. Michael R. Cohen, 10 Over-the-Counter Medicines Abused By Teens, PHILly.COM (Jan. 14, 2013), http://www.philly.com/philly/blogs/healthcare/10-over-the-countermedicines-abused-by-teens.html, archived at http://perma.cc/Y55PHT9T.

129 Fabian Sanchis-Gomar et al., Energy Drink Overconsumption in Adolescents: Implications for Arrhythmias and Other Cardiovascular Events, 31 CANADIAN J. CARDIOLOGY 572 (2015).

130 Vrecko, Just How Cognitive, supra note 54. 
concomitantly, ${ }^{131}$ thus increasing the risk of significant side effects.

\section{Other Considerations}

Health care consumers or patients have access to large amounts of health information of varying quality about cosmetic neurocognitive enhancement outside the providerpatient relationship. People also live in an environment shaped by financial factors, social mores, and policies, all of which influence decision-making. These additional factors are of likely equal to greater significance to most health care consumers or patients than provider opinion on the matter.

If cosmetic neurocognitive enhancement is not a treatment covered by health insurers or employers then the cost will necessarily fall to the individual. Access will be limited to those who can afford to pay for the interventions. This has been a source of ambivalence for providers, who believe that the technologies should be available to consumers as a matter of equality, but who do not believe that enhancement should be covered by third-party payers since they are not medically necessary. The prescription immediate release amphetamines and methylphenidate, which are by far the riskiest of the medications used for neurocognitive enhancement, are also the cheapest and most widely available apart from caffeine. The costs associated with Schedule II drugs are magnified by the

131 Sean Esteban McCabe et al., Non-medical Use of Prescription Stimulants Among US College Students: Prevalence and Correlates from a National Survey, 100 AdDiCTION 96 (2005); Laura M. GarnierDykstra et al., Nonmedical Use of Prescription Stimulants During College: Four-Year Trends in Exposure Opportunity, Use, Motives, and Sources, 60 J. AM. C. HeALth 226 (2012); Herman-Stahl et al., Risk and Protective Factors for Methamphetamine Use and Nonmedical Use of Prescription Stimulants Among Young Adults Aged 18 to 25, 32 AdDictive BeHAV. 1003 (2007); Amelia M. Arria et al., Nonmedical Use of Prescription Stimulants Among College Students: Associations with ADHD and Polydrug Use, 28 PhARMACOTHERAPY 156 (2008); Conrad L. Woolsey et al., Increased Energy Drink Use as a Predictor of Illicit Prescription Stimulant Use, 13 Substance Abuse (2014). 
monitoring that many providers will require to prevent harm. Health care consumers attempting to make decisions about cosmetic neurocognitive enhancement deserve clear information about benefits and risks.

To the extent that cosmetic neurocognitive enhancement is used to navigate difficult social situations, societies are free to make decisions to alter those situations. If educational systems have become so overburdened that classrooms are places of randomness and chaos then a different class structure may be called for, rather than an amphetamine prescription. If there is such a gap between the top schools or workplaces and the next available situation, then it is time to expand the number of favorable educational environments and jobs. If there is recognition that fatigue is associated with significant errors then there could be limits on the numbers of continuous hours that people in high demand and high risk situations are permitted work. And, it might be time to revisit the wisdom of swing shift work. Individuals, enhanced or not, should be exposed to a broader range of options that allow for both the ability to make a living and the opportunity to sleep adequately. Given that they are not, a place for cosmetic neurocognitive enhancement is a part of the landscape of choices that people have in coping with the less than optimal situations with which they are faced.

Public policies that discourage drug use in the work or educational environment tend to reduce the number of individuals reaching for cosmetic neurocognitive enhancement by prohibited substances, be they the cosmetic agents specifically or the substances of abuse that may occasion cosmetic use. Though some may be over-reaching, these policies are generally because of the significant overlap between non-medical users and individuals with substance use disorders, who tend to escalate dose and use many stimulant substances at the same time, ${ }^{132}$ without

132 Hartung, supra note 50, at 835-40; NAT'L Inst. ON DRUG ABUSE, Nat'l Inst. of Health, U.S. DeP't of Health \& Human Serv., Research REPORT SERIES: PRESCRIPTION DRug Abuse 1, available at http://www.drugabuse.gov/publications/research-reports/prescriptiondrugs/stimulants/it-safe-to-use-stimulants-other-medications. 
apparent increase in achievement. ${ }^{133}$ In addition to policies that discourage drug use, effective screening for individuals at risk for substance dependence and time-limited trials of potentially addicting medications are ways to minimize this risk.

The increase in U.S. production of amphetamine stimulants has caused worldwide concern for control of illicit amphetamine production and distribution. Several commentators have noted that the worldwide amphetamine problem cannot be addressed until the prescription of amphetamine substances is curbed by restricting indications, limiting production, or developing alternatives to amphetamines. Though not completely without risk, sustained release and transdermal preparations likely decrease dose escalation and are less attractive agents for diversion. Additionally drugs such as modafinil may represent a promising prototype for a non-amphetamine stimulant. Over time others will likely be developed, particularly if quotas remain in place or tighten.

\section{RECOMMENDATIONS FOR PROVIDERS AND SYSTEMS}

Cosmetic neurocognitive enhancement is not new. Human beings have been using substances to this end for centuries, and some of these substances require the participation of a health care provider. Since many conditions in neurology and psychiatry are based on self report and subjective disability, the issue at this juncture is not whether or not "normal" individuals receive prescribed products for enhancement but involve the process necessary to use these agents safely and the costs associated with such use. 134 Neuroscientific advances in delineating likely drug

133 United Nations Office on Drugs and Crime, The NonMedical Use of Prescription Drugs: Policy Direction Issues, DISCUSSION PAPER 17 (2011), available at http://www.unodc.org/ documents/drug-prevention-and-treatment/nonmedical-useprescription-drugs.pdf.

134 Daniel S. Rizzuto \& Joshua W. Fost, Transhumanism and Cognitive Enhancement, in J. W. Haag et al., THE RoutledGe COMPANION FOR RELIGION AND SCIENCE 569-77 (J. W. Haag et al., eds. 2012). 
effects in given neurobiological systems in various human populations may eventually allow for personalized cosmetic neurocognitive enhancement in which a provider could communicate specific benefits and risks, along with detailed information about trade offs, to the patient or requestor. Such advances could also inform policy that would be helpful in defining who should receive cosmetic enhancement, which situations merit cosmetic enhancement, and how patients, consumers, or requestors should access cosmetic neurocognitive enhancement. 135 Until such advances occur, individual providers will deal with individual requests in systems with varying standards of practice.

Given the very wide variability in provider attitudes, beliefs, and practices concerning cosmetic neurocognitive enhancement, ${ }^{136}$ the health care consumer or patient may receive different answers from different providers about cosmetic neurocognitive enhancement even if the same safety and efficacy data are available to all providers. ${ }^{137}$ This difference in how the individual provider balances the probabilities that the intervention will meet the patient's expressed need, will be used as intended, and will not result in unacceptable side effect burden cannot be regulated. This behavior is the practice of medicine. The provider is under no ethical imperative to provide cosmetic neurocognitive, nor is there any legal or ethical bar to doing so. ${ }^{138}$ There is nothing to suggest that this decision is so qualitatively different from other medical decisions that it merits special training, prohibitions, or rules. While there is not a per se ethical bar to the use of medications for cosmetic neurocognitive enhancement, the risk-benefit

135 Maslen, supra note 47.

136 Megan Brooks, Experts Clash Over Cognitive Enhancers For Healthy People, MEDSCAPE (Dec. 24, 2012), http://www.medscape.com/ viewarticle/776683, archived at http://perma.cc/DU28-RKNW.

137 Hotze et al., Doctor, supra note 15, at 3-13; See also C. Verster \& A A van Niekerk, Moral Perspectives on Stimulant Use By Healthy Students, 102 SAMJ 909, 909-11 (2012).

138 Dan Larriviere et al., Responding to Requests from Adult Patients for Neuroenhancements: Guidance of the Ethics, Law and Humanities Committee, 73 Neurology 1406 (2009). 
analysis of currently available technologies should be carefully considered. ${ }^{139}$

What follows is a proposed practice guideline to inform practice. The process described is time and labor intensive. It will likely also involve the use of a multi-disciplinary team to be efficient and successful. While it is always tempting in busy medical practices to take short cuts, this process relies on meaningful communication between provider and health care consumer or patient. The indeterminacy in the gains and magnitude of the risks involved with cosmetic neurocognitive enhancement are sufficiently high to merit the time, energy, and expense. ${ }^{140}$

1. Listen carefully to the request. Explore goals and expectations of treatment.

2. Perform a thorough diagnostic evaluation including baseline quantification of attention and concentration, objective personality testing, and screening for OTC stimulant use and substance misuse.

3. Consider the relative contributions of mismatched expectations, social stresses, and treatable illness to the perception of less than optimal cognition and encourage the individual to address as many of these factors as possible prior to prescribing medications for the purpose of cosmetic neurocognitive enhancement.

\footnotetext{
139 Cynthia Forlini et al., Should Physicians Prescribe Cognitive Enhancers to Healthy Individuals?, 185 CAN. MED. Ass'N J. 1047, 104750 (2013) [hereinafter Forlini, Should Physicians Prescribe]; Matthis Synofzik, Ethically Justified, Clinically Applicable Criteria for Physician Decision-Making in Psychopharmacological Enhancement, 2 NEUROETHICS 89, 89-102 (2009).

140 Recall that feigning symptoms to secure a prescription for stimulants is more common than previously believed, emergency department mentions are increasing among adults using stimulants, prescription users typically use other substances, family and friends are the most common source of diverted stimulants, and almost two-thirds of students prescribed stimulants for ADHD admitted to diverting them.
} 
4. Provide evidence-based education about cognition and cognitive enhancement. The long-term maintenance of wellness (nutrition, sleep, exercise, socialization, education, and avoidance of toxins and trauma) is most associated with optimal cognition and should be a precondition of cosmetic neurocognitive enhancement using prescribed medications.

5. Provide education concerning the likely effects and side effects of proposed medications for cosmetic neurocognitive enhancement, as well as the cognitive and emotional tradeoffs likely involved in their use. Assess whether requestor expectations align with reasonably foreseeable drug effects.

6. Be transparent about the risks and costs of these medications including the expected side effects, need for frequent follow-up and likely out-of-pocket costs for both the medication and the necessary monitoring.

7. Be clear with the requestor and third-party payer about the indication for the drug and document thoroughly concerning the offlabel use of the medication for cosmetic enhancement of cognition.

8. Plan a short initial trial of medications with monitoring of specific target symptoms before, during, and after the provision of prescribed medications for cosmetic neurocognitive enhancement. Review this data with the patient-consumer prior to initiating longer-term treatment at an agreed upon dose and follow-up interval.

9. Consider a treatment contract with continued prescription of the stimulant dependent upon use of a single provider, compliance with appointment schedule, optimization of non-medication 
interventions, and abstinence from drugs of abuse or dependence as evidenced by a negative urine drug screen. Monitor for dose escalation and consider prompt discontinuation if this occurs or if the prescribed substance is combined with other stimulants.

10. Avoid the use of immediate release amphetamines and methylphenidate for cosmetic neurocognitive enhancement. Individual factors may be sufficient to tip the balance in favor of prescribing sustained release preparations, transdermal preparations and modafinil, all of which come with lower risks of side effects and abuse liability.

11. Evaluate each medication and technology purporting to be useful in cosmetic neurocognitive as it emerges and gauge effectiveness against likely placebo effect and non-pharmacologic strategies for enhancement. The provider has a responsibility to act according to his or her professional expertise and conscience in forming interventions for the health care consumer or patient that have the highest probability of success with the lowest risk of harm.

\section{CONCLUSION}

While the practice of cosmetic neurocognitive enhancement is both legally and ethically permissible, the cosmetic use of currently existing prescribed stimulant medications is unlikely to meet the expectations of health care consumers, patients, or providers or to achieve the lofty goals of societal benefit sometimes proffered as justification for the practice. However, sufficient indeterminacy exists in the purpose of health care, definition of disability, and individual circumstances that providers may wish to offer 
cosmetic neurocognitive enhancement to those requesting it. As time goes on, more pharmaceutical products and technologies will enter the marketplace with the goal of cosmetic neurocognitive enhancement. It is incumbent on providers considering the use of these technologies for cosmetic purposes to research the products fully, develop an approach to deliver the service consistently to those requesting it, and discharge the gatekeeper function. 